\title{
New England \\ Wind Energy Education Project
}

Final Technical Report

DOE Award Number: DE-EE0000518

Project Period (12/09 - 11/11)

Principal Investigator:

Robert C. Grace

508-665-5855

bgrace@seadvantage.com

Authors:

Robert C. Grace

Kathryn A. Craddock

Daniel R. von Allmen

Submitted by:

Sustainable Energy Advantage, LLC

10 Speen Street, Framingham, MA 01701

April 25, 2012 
Acknowledgment: This report is based upon work supported by the U. S. Department of Energy under Award No. DE-EE0000518

Disclaimer: "Any findings, opinions, and conclusions or recommendations expressed in this report are those of the author(s) and do not necessarily reflect the views of the Department of Energy" 


\section{Table of Contents}

\section{Contents}

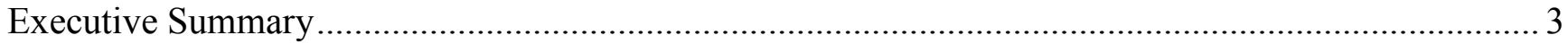

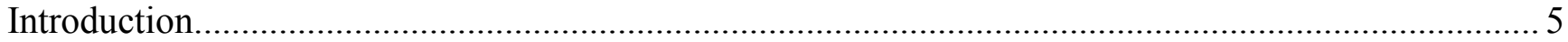

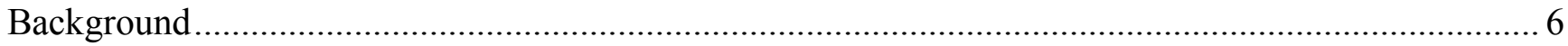

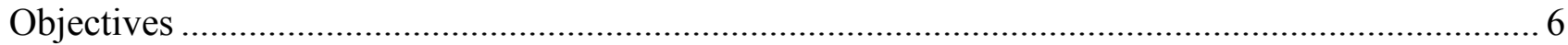

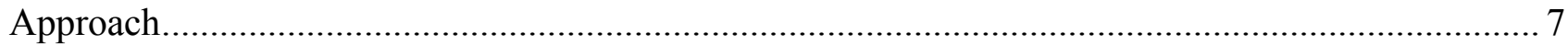

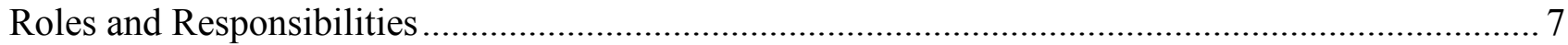

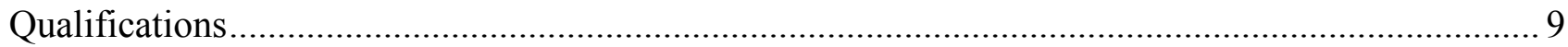

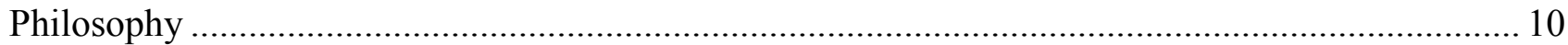

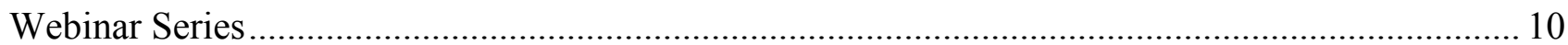

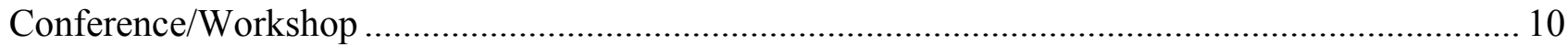

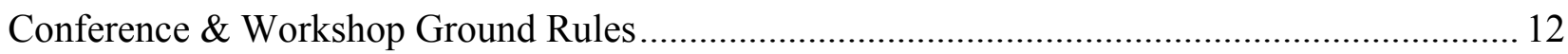

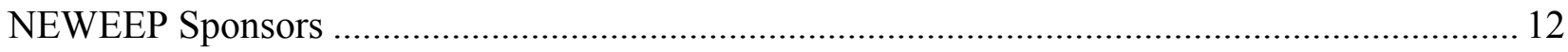

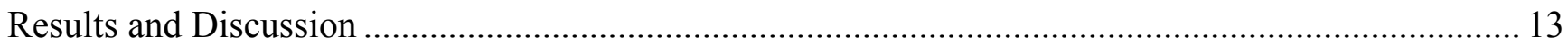

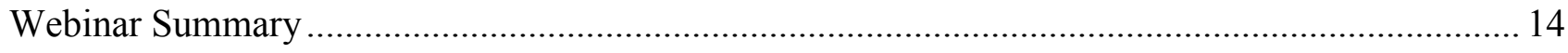

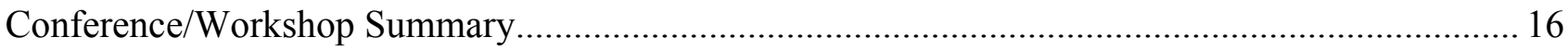

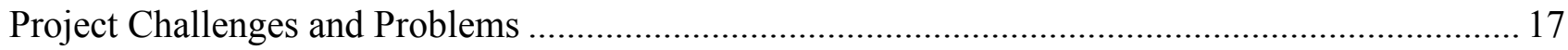

Cost-share Partner Funding and Steering Committee Staffing Issues........................................... 17

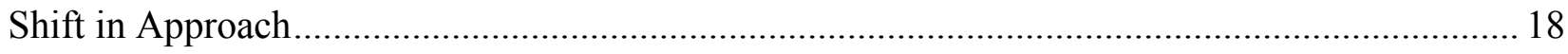

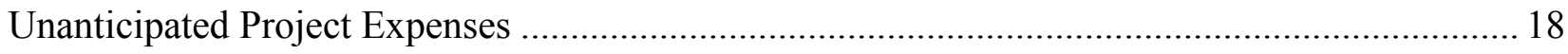

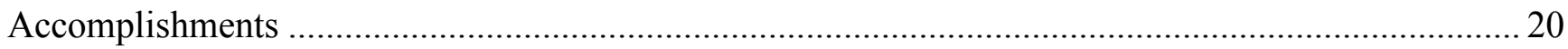

SEA Receives Eastern Regional Wind Advocacy Award …….................................................... 22

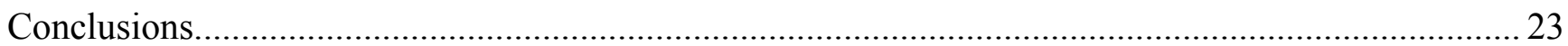

Findings on Wind Public Acceptance Context and Landscape in New England ............................... 23

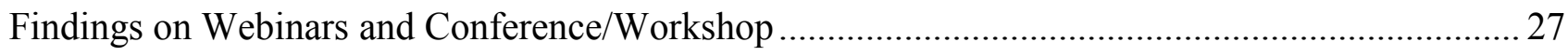

Lessons Learned for Efforts to Support Public Acceptance .......................................................... 28

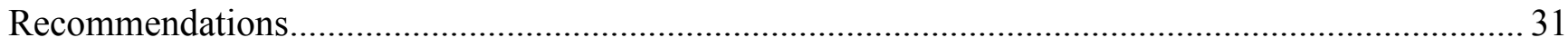




\section{Executive Summary}

There are currently hundreds of wind turbines proposed in the New England region, where high population density and alternative land uses have driven policy makers, abutters, and developers to engage in an ongoing debate over the proper guidelines (if any) for effectively siting new generators. While many of the issues that impact wind's acceptance in the region are common to those affecting wind development elsewhere, New England's demographics, the large number of projects and their proximity to population centers raise a number of unique concerns (i.e. sound, health and visual impacts, wildlife impacts, property values, grid integration and emissions avoidance). For decisionmakers and abutters alike, one of the greatest challenges is finding, processing and disseminating complete and accurate information regarding these issues.

In December of 2008, the Department of Energy issued a funding opportunity entitled " $20 \%$ Wind by 2030: Overcoming the Challenges." In response, Sustainable Energy Advantage, LLC (SEA), in partnership with the National Renewable Energy Laboratory (NREL), proposed the New England Wind Energy Education Project (NEWEEP), which was designed to provide decision-makers and the public with accurate, objective information on critical wind energy issues. The Department of Energy awarded the team a two-year grant under its Wind Powering America 'Market Acceptance' program.

NEWEEP consisted of a series of six webinars and a one-day conference/workshop, all of which are now available online through the New England Wind Forum (NEWF) website. In conducting NEWEEP, SEA served as the project lead, with NREL playing a supporting role. A Steering Committee consisting of New England state agencies, regional and national research organizations and New England's regional grid operator also contributed to the project's implementation. Specifically, the Steering Committee helped to: (1) identify and prioritize topics of greatest interest or concern where detailed, objective and accurate information would advance the dialogue in the region; (2) identify critical outreach venues, influencers and experts; (3) direct and coordinate the activities of project staff; (4) assist project staff in planning briefings and conferences; (5) identify topic areas where additional research or technical assistance is required to fill information gaps; and (6) identify and recruit additional steering committee members and partners to the collaborative.

At the direction of the Steering Committee, the webinar series covered a wide variety of topics deemed most important in the struggle for applicable and accurate information. Topics included: (1) property values; (2) wind turbine sound impacts; (3) health impacts of wind turbine sound (4) grid reliability, backup supply, and fossil fuel use; (5) shadow flicker; and (6) techniques for mitigating public impacts of wind turbines. The webinars saw record attendance and were deemed a success both in terms of the quality of information and the team's attempt to be neutral and objective. In addition, participants found the availability of web-based materials to be very useful. Similarly, the conference was intended to continue to educate concerned stakeholders, engage productive dialogue between all parties, and to promote further work in expanding the body of research, both through NEWEEP and other avenues.

Through these presentations and discussions, NEWEEP provided a wealth of information on many of the issues dominating the wind siting debate and identified specific gaps where further research is needed. While the guiding philosophy of NEWEEP encourages each individual to use the web-based materials to reach their own conclusions, it is possible to provide some high-level summary of the information that was brought to light. 
First, it is important to summarize the current policy and siting climate - one which is rife with conflicting information, competing claims, and research of varying degrees of academic rigor. Often this evidence is presented in a way that makes one source indistinguishable from another, and both decision-makers and concerned citizens are ill-equipped to tell the difference. These participants can generally be grouped into several broad categories: (1) proponents, who are often viewed by others as motivated by commercial interests, regardless of the accuracy of this assumption; (2) open-minded abutters, who are typically community groups simply looking for accurate information to help them take a stance on siting issues;; and (3) project opponents, who are more accurately grouped into several subcategories. First, "skeptics" are those who are disinclined towards wind and require a high burden of proof to be convinced otherwise. Second, "character of place" groups support wind, but not in a given location, whether for environmental, aesthetic or other reasons. Third, community based abutters are those who live in close proximity to a proposed site and will receive minimal (if any) upside from the installation and are therefore resistant to bearing potential negative impacts. Finally, the "ideologically-opposed" are perhaps the most complicated subset of project opponents. These participants are often involved with highly-sophisticated and networked anti-wind groups that work together to disseminate a combination of information ranging from accurate to rhetorical spin designed specifically to represent wind energy in a universally negative light.

This climate of conflicting information and ideological differences has resulted in an emotionally charged debate that makes it increasingly difficult for decision-makers to base their assessments strictly on facts. As a result, an increasing number of projects are being turned down at the local level and the lengthy appeals process (though rarely successful after initial project approval) adds a significant cost-burden to developers. Communities across the region are adopting strict zoning regulations or outright bans on wind development. Most importantly, when doubt and uncertainty enter the debate, decision-makers historically refer to the status quo (no project). This makes siting projects progressively more challenging, regardless of whether or not they are appropriately located.

Further complicating the discussion, changes in the availability and prices of electricity have brought about new market conditions that have fundamentally transformed the debate. These new variables include the downward pressure on prices driven by the shale gas boom and global recession. The recession has also brought about a change in public priorities that favors short term economics over long-term sustainability, as well as a surplus of generation due to reduced overall demand. In addition, the high costs of transmission system expansion (and the issue of who should bear them) has limited development of the substantial, but remote resources of northern New England. Fundamental disagreements over the role of subsidies, intermittency, and the inherent benefits (economic and environmental) of wind power also contribute to the growing confusion and further impress the need for clear and accurate information.

Based on the overwhelmingly positive response from NEWEEP participants, SEA, NREL and the Steering Committee took some significant steps towards reaching this goal; however, the team also identified specific areas for improvement and opportunities for future work. Specifically, the project would have benefited from increased participation from the "ideologically-opposed" and members of the media. This would have produced a more well-rounded dialogue and would hopefully take steps towards eliminating some of the hyperbole and inflammatory language that is common in news reports and public siting meetings. The challenge of presenting information as unbiased is also deserving of more attention, but is difficult given the scarcity of funding available from independent and government sources. Despite these challenges and shortcomings, there is still widespread support for the continuation of NEWEEP or a similar program. 


\section{Introduction}

Hundreds of wind installations have been proposed in the densely-populated region New England region, where the windiest locations are often prized for other purposes. Where wind energy projects are proposed, communities are often faced with valid questions and concerns from abutters and information on impacts offered up by not just project proponents but also parties from outside the local communities. In this context, decision-makers need a place to turn.

In December of 2008, the Department of Energy issued a funding opportunity entitled " $20 \%$ Wind by 2030: Overcoming the Challenges." Sustainable Energy Advantage, LLC (SEA) and the National Renewable Energy Laboratory (NREL) proposed a project based on information dissemination about issues impacting the public acceptance of wind power in response to the Market Acceptance task under this Funding Opportunity Announcement, and this team was awarded a twoyear grant.

The New England Wind Energy Education Project (NEWEEP) was designed to provide siting decision-makers and the potentially-impacted public with accurate, objective information on critical wind energy issues on which to make informed decisions about the siting of proposed wind energy projects throughout New England. NEWEEP's role has been to attempt to cut through the clutter of competing, conflicting and sometimes misleading information on critical issues, helping to address concerns raised in communities where wind projects are proposed. By providing information on what is known about wind power's benefits and impacts, as well as identifying information gaps, the NEWEEP team hoped to improve prospects for enhancing the region's market acceptance of appropriately-sited wind energy generation.

NEWEEP consisted of a webinar series and a one-day conference/workshop focused on addressing the issues impacting public acceptance of wind projects. It also consisted of creating a web-based repository for the proceedings.

NEWEEP was established with the belief that successful execution of this project would help close gaps in understanding, and either support good information or counteract misinformation advanced by either project proponents, opponents or both. NEWEEP's efforts aimed to reduce misconceptions and highlight the true problems as well as identify solutions to work through these issues. The webinar series and conference/workshop focused on addressing these critical issues and concerns raised in communities where wind projects are proposed.

While it may be difficult - both now and in the future - for all stakeholders to agree on which precise initiative, dialogue or event led to the acceleration and construction of wind generation in New England, the region's wind stakeholders already agree that NEWEEP is one of the tools necessary to remove the barriers to market acceptance. The willingness of all the partners committing their resources to this effort was the most important expression of the dedication and belief in the project's objective. NEWEEP can continue to provide the central function of ensuring that New England has access to accurate and objective information concerning wind energy development once the right funding mechanism is secured.

Although this project is complete, the product of NEWEEP's efforts is available online as a resource to be used broadly within region and beyond. The webinar, conference presentations, and ancillary materials remain posted on the New England Wind Forum website hosted within the Wind Powering America web site. 


\section{Background}

The issues that impact wind's market acceptance in the region are numerous, and while many of the topics are common in nature to those affecting wind development elsewhere, New England's demographics, the large number of projects, and their proximity to population centers - including numerous 'urban turbines' - make some issues more important to the region than others. Stakeholders in communities where projects are being proposed are barraged with conflicting information on a range of issues associated with wind energy, including such topics as sound, health and visual impacts; bird, bat and other wildlife impacts; property values, 'back up' requirements for wind variable generation, integration with the electric grid, emission avoidance, and economic development.

Many issues impacting wind power public acceptance are well understood and supported by sound and rigorous research; however, there are still a number of topics that are not well-understood. While developers and industry associations will provide those in the community with ample information, such information cannot be taken as objective, coming from parties with a commercial interest in that project moving forward. At the same time, those opposed to projects may also express viewpoints, sometimes supported by accurate data, but often containing incomplete, misleading or incorrect information. Members of the public and other stakeholders typically have many concerns, ranging from valid to unfounded. Unfortunately, there was no place to turn for accurate, objective information on these wind issues.

A shift in the wind power siting dialog was observed over the course of the project. As wind projects in the region became more prevalent and turbines have gotten bigger, and closer to more people, the nature and frequency of conflicts over siting and public acceptance appeared to grow. These observations were manifested in increasing frequency of contested siting instances and inflamed by both the sensationalistic nature of press coverage (tending to report on a small number of complaints in a way that left the reader with distorted impressions of the prevalence and magnitude of abutter impacts) and the increasing sophistication and reach via the internet of both organized antiwind groups as well as concerned citizens groups.

\section{Objectives}

NEWEEP was designed to provide siting decision-makers and the potentially-impacted public with accurate, objective information on critical wind energy issues on which to make informed decisions about the siting of proposed wind energy projects throughout New England. NEWEEP's role has been to attempt to cut through the clutter of competing, conflicting and sometimes misleading information on critical issues, helping to address concerns raised in communities where wind projects are proposed. While much is not known, by providing information on what is known, as well as identifying information gaps, the NEWEEP hoped to improve prospects for enhancing the region's market acceptance of appropriately-sited wind energy generation.

NEWEEP was designed to be inclusive in the search for good, accurate, objective information. Objectivity is an ideal to strive for, but one acknowledged as difficult to reach, and is in the eye of the beholder. Yet our society has developed standards and approaches of research and review which, when applied, must carry greater weight than opinion and rhetoric. It is NEWEEP's mission to seek and make available the best information possible to support good decisions. 


\section{Approach}

NEWEEP consisted of a series of 6 webinars covering 8 topics, and a one-day conference/workshop. These initiatives were focused on addressing the issues impacting public acceptance of wind projects. NEWEEP also created a web-based repository for the proceedings. NEWEEP's approach was comprised of a series of recurring webinars, culminating in a day-long conference/workshop in the second year. The repetition of NEWEEP events was a deliberate, and important, design feature. The frequency of events not only allowed NEWEEP to cover a broad range of topics without overwhelming its audience, but also allowed the collaborative to condition stakeholders to participate in - and rely on the resulting information from - NEWEEP on a consistent and ongoing basis. In other words, NEWEEP's goal was not only to research, develop and assemble objective information, but also to create a strong, branded reputation as the most comprehensive and reliable wind energy information resource in the region.

In conducting NEWEEP, SEA served as the project lead, with NREL playing a supporting role. A Steering Committee, consisting of New England state agencies, regional and national research organizations and New England's regional grid operator, also committed to participate in the project. The Steering Committee served as an initial group of collaborators to help guide the project and advise SEA in managing all project activities. Additional Steering Committee members were recruited throughout the term to enhance the project's impact, reach and effectiveness. With the help of the Steering Committee, NEWEEP sought to spur discussion and progress on local wind siting issues by leveraging a collaborative effort of state, regional and federal resources to achieve the projects' objectives.

The Steering Committee helped to: (1) identify and prioritize topics of greatest interest or concern where detailed, objective and accurate information would advance the dialogue in the region; (2) identify critical outreach venues, influencers and experts; (3) direct and coordinate the activities of project staff; (4) assist project staff in planning briefings and conferences; (5) identify topic areas where additional research or technical assistance is required to fill information gaps; and (6) identify and recruit additional steering committee members and partners to the collaborative.

\section{Roles and Responsibilities}

SEA coordinated planning call agendas, webinar and conference logistics, developed outreach materials and distributed to the outreach partners. SEA conducted regular Steering Committee and subcommittee teleconference meetings, developed and maintained an annotated bibliography related to webinar content, and gathered other related research. NREL's role included hosting the New England Wind Forum (NEWF) website, where NEWEEP's web pages reside, posting webinar and conference materials for public access, providing the technology to conduct the webinars, participating in webinar and conference/workshop planning calls, and assisting with outreach. NREL also participated in the Steering Committee and topical subcommittees, and contributed research and speakers to webinars and the conference.

The initial group of Steering Committee members and partners were actively recruited prior to the funding proposal, and each committed to support NEWEEP. To achieve the project's objectives, SEA and NREL believed that it was critically important that the project be seen as credible and objective, and therefore not wind industry-driven. For that reason, the Steering Committee consisted of: 
- policy leaders representing New England states' regulatory and renewable energy funding offices;

- technology leaders, both national and local; and

- representatives of key utility organizations responsible for addressing acceptance of wind energy onto the grid and into wholesale power markets.

While it was critical that the steering committee be driven by those without commercial interest in the outcome of a particular wind energy project or even wind energy as a whole, participation of other entities - including wind developers and others engaged in siting or building wind projects, and non-governmental organizations active in the area - was also critical to identifying and prioritizing information needs. For this reason, a newly-formed organization called Renewable Energy New England (RENEW) was invited to participate in the Steering Committee. RENEW, modeled after regional industry-environmental advocate partnerships in other regions (see ACE New York,

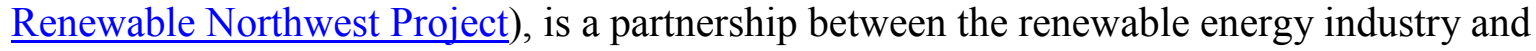
environmental public interest groups working in New England to increase renewable energy in New England. RENEW's participation allowed such organizations a single seat at the table and a voice, while playing a sufficiently minor role so as not to impair the project's objectivity.

The Steering Committee identified and recruited the best experts to speak and present via the webinars and the conference/workshop on the issues deemed as priorities for New England. The approach in conducting the webinars and conference incorporated the following:

- Issue identification

- The 'state of the art' of knowledge on the topic, relying on credible, peer reviewed research

- Discussion of pros and cons, and the range of different perspectives on the issues

- Lessons learned from experience elsewhere and best practices for mitigating market acceptance issues

Steering Committee members included:

- National Renewable Energy Laboratory (NREL) - original

- Utility Wind Integration Group (UWIG) - original

- Independent System Operator of New England (ISO-NE) - original

- The University of Massachusetts Wind Energy Center (WEC)* - original

- Massachusetts Clean Energy Center (MA CEC) [formerly The Massachusetts Renewable Energy Trust (Trust)] - original

- Efficiency Maine, a division of the Maine Public Utilities Commission (MPUC/EM)* original

- The New Hampshire Office of Energy and Planning (NH OEP) - original

- The Connecticut Clean Energy Fund (CCEF) - original

- Renewable Energy New England (RENEW) - original

- Lawrence Berkeley National Laboratory (LBNL) - original

- Clean Energy Group, Clean Energy States Alliance (CESA) - new recruit

- Massachusetts Department of Energy Resources (MA DOER) - new recruit

- The State of RI Office of Energy Resources (RI OER) - new recruit 
(*) as discussed further below, these organizations curtailed their participation during the course of the project due to changes to their mandates or funding.

Separate from the Steering Committee listed above, the following individuals also volunteered to participate in NEWEEP's conference planning committee:

- Zywia Wojnar, Research Director for Pace Energy and Climate Center at Pace Law School;

- Sue Jones, Chief Executive Manager for Community Energy Partners and coordinator of the Maine Wind Working Group;

- Walker Larson, Project Specialist for Conservation Law Foundation's CLF Ventures;

- Andrew J. Kostrzewa, Project Manager for Rhode Island Division of Planning;

- David McGlinchey, Senior Program Leader-Energy and Environment for Manomet Center for Conservation Sciences; and

- Pat Quinlan, formerly Associate Director of UMASS Amherst Wind Energy Center.

\section{Qualifications}

For over a decade, SEA has been a leader in renewable energy policy and analysis in New England. Through its provision of renewable energy market, business, policy and financial analysis to a broad range of both public and private sector clients, SEA is tuned into both the subtleties and the big picture of New England's renewable energy marketplace. Further, since 2001 SEA has been intimately involved in the development of strategies and initiatives that led to this project. From the first New England Windpower Workshop in 2001 to the New England Wind Forum (2005 to present), NREL and a host of regional and local partners have demonstrated their confidence in SEA by continuing to sign-on to initiatives and proposals in which SEA participates. SEA and its partners had demonstrated the necessary skills and successfully executed the NEWEEP initiative.

Sustainable Energy Advantage is the editor and content provider for the New England Wind Forum (NEWF) website and newsletter. NEWF is a Wind Powering America (WPA) initiative, consisting of a web site hosted within the broader WPA web site and maintained by NREL and an electronic newsletter. SEA develops the content and NREL maintains and hosts the web site, the email list of opt-in newsletter subscribers, and formats and distributes the newsletter. NEWF was started several years ago and has been financially supported (at various times) by NREL and/or the four state agencies who were also participants in NEWEEP: MASS CEC, MPUC/EM, NH OEP and CCEF. The objective of the NEWF project was to create an information vehicle for information on wind development and policy in New England, maintain an events calendar, to provide content on and links to information on wind resources and wind-related issues - a place for regional stakeholders to turn for objective information. NEWF strives to help citizens, communities and governments make good, educated decisions through its website and periodic newsletter.

- Web site: The site includes content on state policies impacting wind, a regional wind project map, state by state wind project status and issue updates, a calendar of regional meetings and events, and links to appropriate web sites. It also serves as a portal to regional wind resource maps and other WPA resources. Additionally, the website has expanded to include NEWEEP webinar and conference/workshop materials.

- Newsletter: SEA developed and electronically distributed a newsletter on New England wind development activity, issues, actions, and perspectives.

In addition to tracking the progress of approximately 270 wind energy projects operating or under development throughout New England, and maintaining up-to-date summaries of renewable 
energy policies in these states, SEA has researched and developed content for the NEWF website and newsletter on a number of other wind energy-related topics. Such topics have included (1) the economics of wind energy; (2) technical challenges including grid integration; (3) wind resources in New England; (4) siting considerations; (5) public acceptance; ; and (6) the role of wind power under the Regional Greenhouse Gas Initiative.

SEA also created a broad network of regional stakeholders and established a large peer review group during the NEWF development process. These stakeholders include state and federal regulatory or renewable energy funding agencies - many of whom committed to NEWEEP - as well as a broad group of individuals with a diverse set of perspectives and interests.

\section{Philosophy}

NEWEEP was created based on the premise that wind energy has benefits and that responsiblysited wind power has a role to play in New England, but not every place is the right place for wind generation. Our society needs energy, and no energy source available, including wind power, is free of undesirable impacts. Wind power is not as free of consequence as its most ardent supporters would hope (and sometimes represent), and the consequences of wind power are rarely as dire as made out to be by wind power's most ardent skeptics. To succeed in "doing it right" -- minimizing or mitigating negative impacts to a reasonable degree -- decision-makers and the public need factual information to inform their siting decisions.

\section{Webinar Series}

The objectives of the webinar series included:

- Cutting through the clutter of competing, conflicting and sometimes misleading information on critical issues pertaining to wind energy generation

- Helping to address concerns in communities where wind projects are proposed

- Identifying areas for future research ("data gaps")

Topics were indentified and prioritized by the Steering Committee. Briefing topics included: (a) property values; (b) wind turbine sound impacts; (c) health impacts of wind turbine sound; (d) grid reliability, backup supply, and fossil fuel use; (e) shadow flicker; (f) techniques for mitigating public impacts of wind turbines.

The Steering Committee and project staff identified and recruited experts to speak on the issues deemed as priorities for New England. In some cases, those experts were part of the team: the project staff, Steering Committee member organizations, and other partners. In other cases, they were identified and recruited from other relevant organizations.

\section{Conference/Workshop}

The conference/workshop was intended to accomplish a series of related objectives including:

\section{- Education:}

- Providing an overview of the context, climate and status of wind development in New England.

- Reviewing and recapping for a diverse and primarily lay audience what is well-understood about issues impacting the public acceptance of wind power installation in New England 
(the subject of prior and future webinars) as well as identifying what is not known, highlighting areas where more work/understanding is needed, and where questions, research, technology, legal and process concerns need to be addressed.

\section{- Dialogue:}

○ Allowing stakeholder concerns to be shared in a civil fashion and discussed intelligently and constructively.

\section{- Progress:}

- Defining, advancing, and exploring means to fund required research in a manner that will be perceived as credible.

- Facilitating information exchange and networking.

○ Identifying strategies for continuing and enhancing the NEWEEP effort.

The first part of the day was organized in a conference format with an initial plenary session laying the foundation for the day, as well as parallel tracks to address topics likely to be of interest to different segments of the overall audience. This portion of the program also incorporated a UWIG session which had initially been conceived of as separate but co-located and sequential event, but which the Steering Committee agreed would better serve as part of an integrated conference.

The later part of the day was organized in a workshop format, with the intention of maximizing participant interaction and dialogue. These sessions were aimed at advancing specific issues, such as identification and funding of the research agenda, sharing and disseminating information and experience among local siting officials, and how to improve wind siting outcomes. This portion of the agenda featured facilitated breakout sessions, followed by a final plenary where the results of the breakout discussions were shared.

The subject matter was geared to be inclusive and accessible to a broad audience. The conference/workshop was intended for:

- Policy implementers - including state, regional, and local regulatory/planning authorities; municipal officials (e.g. selectmen, planning board, board of health, etc.); siting and permitting officials and staff;

- Policymakers - including legislators, politicians, and regulators;

- Engaged citizens - including those impacted by existing or planned wind power projects, members of local energy committees, and community organizations either supportive of or concerned about wind energy in their midst;

- Educators, students, utility representatives, the press, and members of the general public interested in learning more about wind energy;

- The wind development community.

Additionally, NEWEEP provided a unique opportunity to all registrants to get involved and help prioritize the afternoon workshop topics by ranking workshop topics in order of importance and by suggesting other topics they felt should be included in the workshop sessions. Over 70 registrants responded to the pre-conference questionnaire. NEWEEP also invited the conference attendees to provide suggestions on how NEWEEP could continue its effort to initiate and expand upon the dialog 
on appropriate wind deployment in New England and move forward with these efforts in a constructive manner.

\section{Conference and Workshop Ground Rules}

In an effort to constructively engage the diverse audience in civil dialogue, the conference committee established the following terms of engagement for attendees to agree to prior to registration and attending the conference:

I. The meeting is without prejudice. To encourage open, honest, and creative dialogue in the best spirit of debate, all participants agree that views and statements made in the meeting will not be used in any way to discredit, defame, or attack them in or after the meeting.

II. Participants will communicate with mutual respect, and agree to discuss civilly. Only one person will speak at a time as called upon by the facilitator and participants will refrain from personal attacks.

III. Each person will express his or her own views rather than speaking for others, will not attribute motives to others, nor make generalizations about community perspective without documented evidence to the fact.

IV. Participants should do their best to distinguish facts and evidence from opinion when they speak, and if possible be prepared to site or provide reference to information provided.

V. Participants will seek understanding rather than imputing motives or attributes to others.

VI. Everyone comes with preconceived notions, but all should be prepared to observe and to listen more than speak. Each person is encouraged to generate options and ideas without commitment.

VII. To advance NEWEEP's mission, each person will seek to identify areas of common ground, without glossing over or minimizing legitimate disagreements, as well as to identify where common ground may be achieved through further research and dialogue.

\section{NEWEEP Sponsors}

DOE funding alone was not sufficient to fully meet the ongoing needs for NEWEEP activity. The Steering Committee aimed to keep attendance fees low (so as to keep the conference accessible to the target audience), and so sought to identify additional financial support through other government, foundation and non-profit sources. Sponsorships were not sought from wind developers or manufacturers, entities whose prospects were most directly linked to specific wind siting outcomes. However, with tight budgets all around, opening sponsorship more broadly was necessary to provide NEWEEP with adequate funds to host the NEWEEP conference and future webinars, and to make the conference attendance affordable. In order to achieve the necessary funding targets, the Steering Committee also sought sponsorship from technical service firms and law firms whose services are, in principle, available to any interested party, and whose compensation is not typically tied to a specific siting outcome. While some of the conference sponsors work largely or even exclusively for the wind development sector, our sponsorship approach was necessary to accommodate current financial realities. The challenge to funding this effort brought to light a broader challenge that needs to be explored of how to fund a credible and independent research effort when sources of funding from those other than the industry are scarce. 


\section{Results and Discussion}

NEWEEP's webinar series and conference/workshop resulted in a collection of a wide array of objective information and specific resources that address the public's concerns relating to proposed and operating wind projects in New England. This information resides on the New England Wind $\underline{\text { Forum's }}^{1}$ website and includes the following materials:

- webinar audio recordings, presentations and bibliographies; and

- conference video, audio files and presentations.

The webinar series covered 8 topics identified and prioritized by the Steering Committee, as shown in Table 1. Figure 1 below provides the number of registrants per webinar and Figure 2 provides the breakdown by registrant type. The webinars attracted a large number of registrants, however, due to circumstances beyond NEWEEP's control, the third webinar consisting of a co-sponsored, in-person event broadcasted online, had the shortest outreach period (3 days) which impacted the number of online registrations. The series included the following topics:

Table 1: Summary of NEWEEP Webinars

\begin{tabular}{|c|c|}
\hline Webinars & Number of Topics Covered Per Webinar \\
\hline $\begin{array}{l}\text { Impact of Wind Power Projects on Residential } \\
\text { Property Values }\end{array}$ & 1 \\
\hline $\begin{array}{l}\text { 2. Understanding the Impacts of Wind Turbine } \\
\text { Sound }\end{array}$ & 1 \\
\hline $\begin{array}{l}\text { 3. Wind Turbine Noise and Health: Fact vs. } \\
\text { Fiction }\end{array}$ & 1 \\
\hline $\begin{array}{l}\text { Wind Power's Impact on Grid Reliability, } \\
\text { Backup Supply, and Fossil Fuel Use in New } \\
\text { England }\end{array}$ & 2 \\
\hline $\begin{array}{l}\text { 5. Understanding the Current Science, Regulation } \\
\text { and Mitigation of Shadow Flicker }\end{array}$ & 1 \\
\hline $\begin{array}{l}\text { 6. Wind Power as a Neighbor: Experience with } \\
\text { Techniques for Mitigating Public Impacts }\end{array}$ & 2 \\
\hline Total \# of Webinar Topics: & 8 \\
\hline
\end{tabular}

\footnotetext{
${ }^{1}$ http://www.windpoweringamerica.gov/newengland/neweep/index.asp
} 


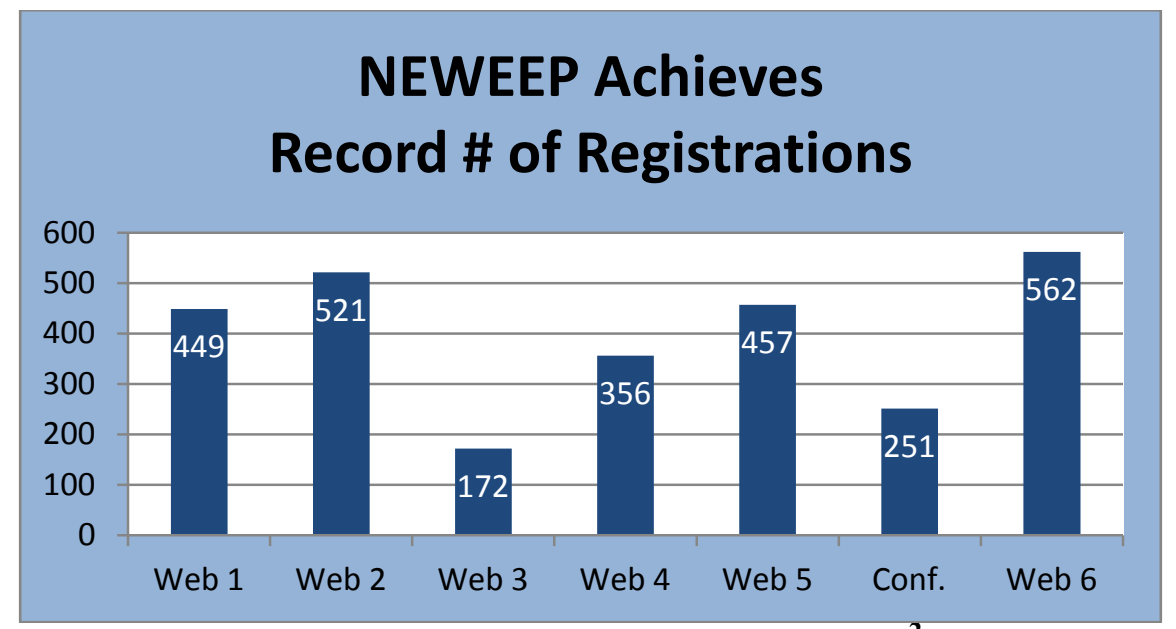

Figure 1 No. of Registrants by Event ${ }^{2}$

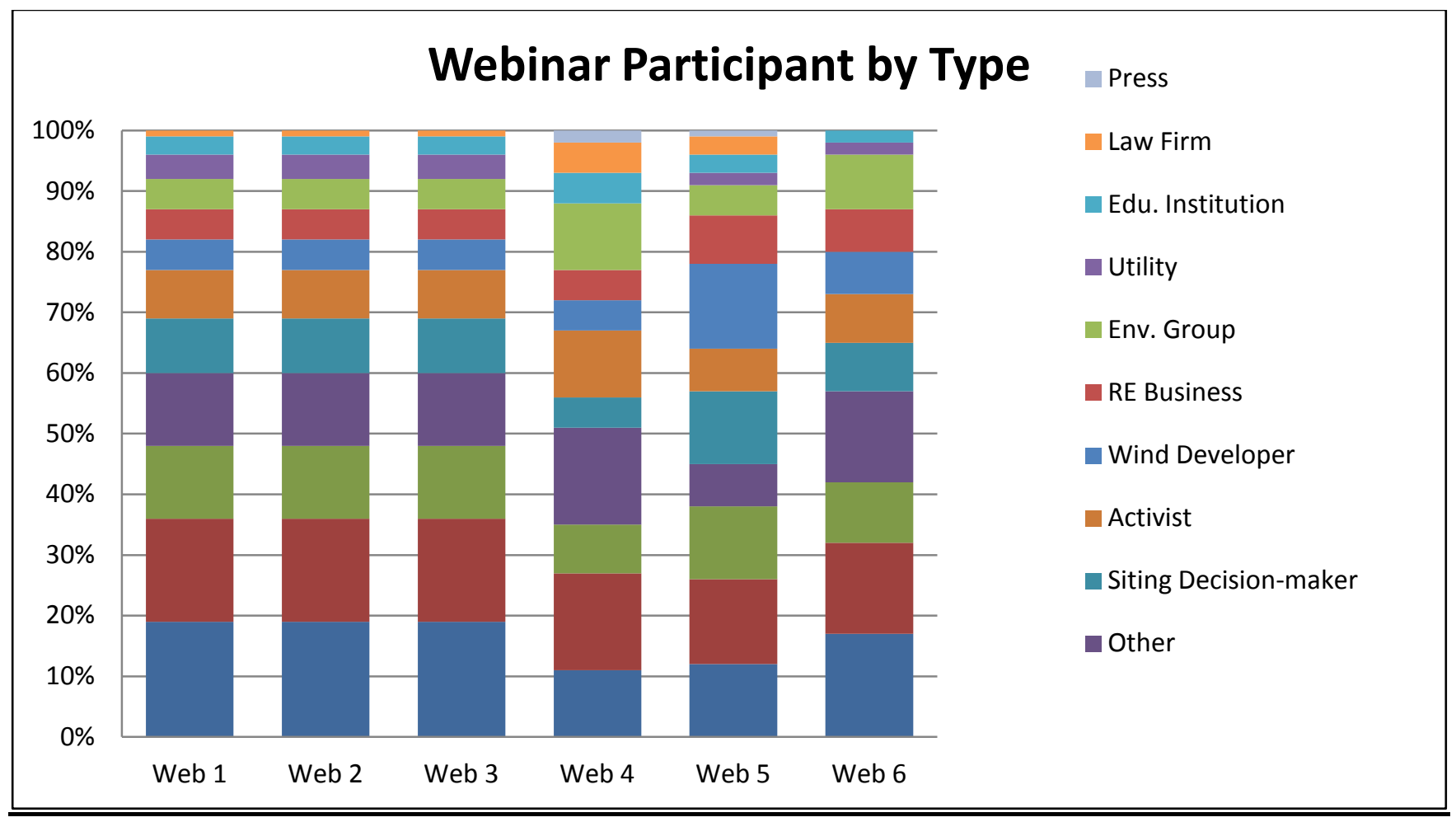

Figure 2 Webinar Participant by Type

\section{Webinar Summary}

Audio visual files and transcripts of webinars hosted by NEWEEP can be found on the New England Wind Forum Web Site. ${ }^{3}$

\footnotetext{
${ }^{2}$ Webinar 3 was a hybrid live event co-broadcast as a webinar. The number shown here is the number of registered webinar participants.

${ }^{3}$ http://www.windpoweringamerica.gov/newengland/neweep/webinars.asp.
} 
The first webinar was held on Wednesday, May 5, 2010, titled "Impacts of Wind Power Projects on Residential Property Values.” Bob Grace of SEA, the NEWEEP Principal Investigator, provided an overview of NEWEEP and moderated the webinar. The feature presentation was given by Ben Hoen, a consultant to the Lawrence Berkeley National Laboratory. Heather Hunt, Executive Director for New England States Committee on Electricity (NESCOE), also presented on "Introduction on Wind Power's Role in Achieving Regional Policy Objectives." The webinar had a total of 449 registrants with over 400 attendees ${ }^{4} ; 75 \%$ of the registrants were from the New England Region. The registrants included participants from 22 different states and Canada.

\section{Understanding the Impacts of Wind Turbine Sound and Wind Turbines Noise and Health: Fact vs. Fiction - Webinars 2 and 3}

During the third quarter of 2010, NEWEEP hosted a two-part webinar series on the impacts of wind turbine sound. Part I (Webinar \#2), "Understanding the Impacts of Wind Turbine Sound" was held on July 13, 2010 consisting of a panel of experts discussing the impacts of wind turbine generator sound, permitting issues, and mitigation. Bob Grace provided an overview of NEWEEP and moderated the webinar. The panel included:

- Mark Bastasch, Lead Acoustical Engineer at CH2M Hill;

- Ken Kaliski, Director of Environment, Energy, and Acoustics at Resource Systems Group;

- Jim Cummings, Executive Director of Acoustic Ecology Institute.

This webinar had a total of over 500 registrants; 74\% from the New England region. The registrants included individuals from 28 different states, Canada and Finland.

Part II of this two-part webinar series (Webinar \#3), "Wind Turbines Noise and Health: Fact vs. Fiction" featuring Dr. Robert McCunney, M.D. was held on July 15, 2010. NEWEEP co-sponsored this simulcast (in-person presentation simultaneously broadcasted via the web) with the Cape and Islands Renewable Energy Collaborative (CI RENEW). The in-person portion of the event was hosted at the Upper Cape Cod Technical High School in Bourne, MA and had over 100 local residents in attendance in addition to those participating via the webinar.

Wind Power's Impact on Grid Reliability, Backup Supply, and Fossil Fuel Use in New England $\underline{\text { Webinar } 4}$

During the fourth quarter of 2010, NEWEEP hosted its fourth webinar on October 26, "Wind Power's Impact on Grid Reliability, Backup Supply, and Fossil Fuel Use in New England." The webinar consisted of a panel of experts discussing the impact of wind's variability on power systems and review of the preliminary results of the New England Wind Integration Study (NEWIS). The panel included:

- Ed DeMeo, President, Renewable Energy Consulting Services, Inc., Technical Advisor: Utility

\footnotetext{
${ }^{4}$ The attendance rate was actually higher than is reported here as it is common for registrants to gather in one conference room to participate collectively in the webinar; participants who dial in by phone but do not log in to the webinar are not tracked in this statistic either. We are unable to estimate the actual number. These figures do not include those that have viewed the recorded webinar online.
} 
Wind Integration Group (UWIG);

- Michael Milligan, Ph. D., Principal Analyst, National Wind Technology Center of National Renewable Energy Laboratory (NREL);

- Bill Henson, Senior Engineer, Renewable Resource Integration, Independent System Operator of New England (ISO-NE).

Bob Grace kicked off the session with a brief overview of NEWEEP and moderated the webinar. With a total of 356 registrants, the registrants comprised 58\% from the New England region, and represented 27 states, England and Pakistan.

\section{Understanding the Current Science, Regulation and Mitigation of Shadow Flicker} - Webinar 5

During the first quarter of 2011, NEWEEP hosted its fifth webinar on February $10^{\text {th }}$, "Understanding the Current Science, Regulation and Mitigation of Shadow Flicker." The webinar consisted of a panel of experts discussing the impacts of shadow flicker caused by wind turbines, methodologies used to forecast when, where and how much flicker will occur, available mitigation and management practices and areas in need of additional research and analysis. The panel included:

- Thomas Priestley, Senior Environmental Planner, CH2MHill;

- Matthew Allen, Principal, Saratoga Associates;

- Richard Lampeter, Senior Scientist, Epsilon Associates.

Jason Gifford, a Senior Consultant at SEA, kicked off the session with a brief overview of NEWEEP and moderated the webinar. Over 450 individuals, from 32 states, Denmark and Canada, registered for the webinar.

Wind Power as a Neighbor: Experience with Techniques for Mitigating Public Impacts Webinar 6

During the fourth quarter of 2011, NEWEEP held its final webinar, "Wind Power as a Neighbor: Experience with Techniques for Mitigating Public Impacts." The webinar consisted of a panel of experts that presented on approaches to minimize, eliminate or compensate for impacts from all phases of wind power projects, lessons learned, keys to successful siting and additional research that is needed. The panel included:

- Charles Newcomb, Wind Technology Deployment Supervisor, National Renewable Energy Laboratory;

- John Knab, Town Supervisor, Sheldon, NY; and

- Nils Bolgen, Program Director, Massachusetts Clean Energy Center.

Bob Grace kicked off the webinar with a brief overview of NEWEEP and moderated the webinar. Over 560 individuals, from 36 states, Canada and India, registered for the webinar.

\section{Conference/Workshop Summary}

During the second quarter of 2011, NEWEEP hosted its one-day conference/workshop on June 7, 2011 in Marlborough, MA, a location selected as central to the region. NEWEEP recruited 50 speakers, moderators and/or discussion panelists to participate in the conference. Over 20 presentations 
were developed and posted on the NEWF website. There were over 250 attendees and 33 actively recruited sponsors. Registrations fees, sponsorships and the grant were used to fund the execution of the conference/workshop. Figure 3 below illustrates the attendee demographics. The proceedings (audio, video and presentations) can be found on the New England Wind Forum Web Site. ${ }^{5}$

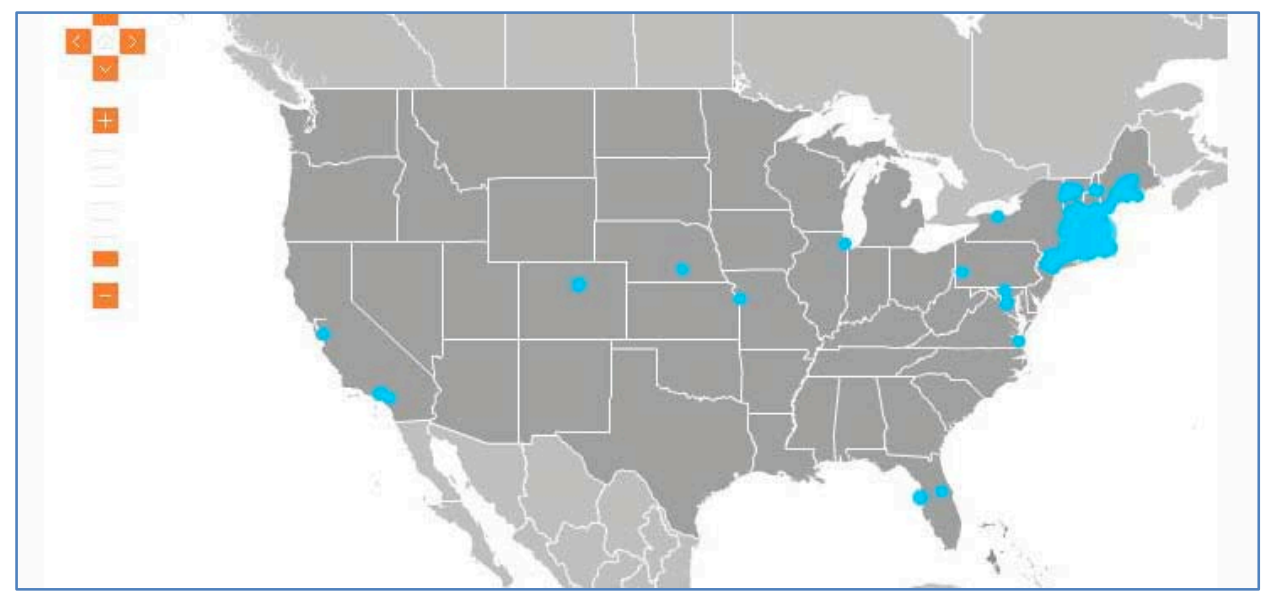

Figure 3: NEWEEP Webinar Attendee Demographics

\section{Project Challenges and Problems}

\section{Cost-share Partner Funding and Steering Committee Staffing Issues}

A few steering committee partners that committed in the NEWEEP grant funding proposal to document an in-kind contribution of labor to the project experienced funding reductions that impaired their ability to continue to contribute to NEWEEP at the levels specified (in particular, UMass WEC lost nearly all of its funding). In anticipation of the potential need to fill these gaps in partner in-kind contributions, and in consultation with the DOE Field Project Officer, SEA continued to reach out to other steering committee partners who had not originally committed to make in-kind commitments, and requested their assistance in supplementing our in-kind contribution requirements to assure SEA met its commitments. The request to submit quarterly timesheets and related documentation was made to other partners, in order for SEA to provide the supporting documentation that the in-kind contribution requirement was met. This additional time tracking was expected to cover all in-kind obligations.

In 2010, the original Maine government Steering Committee partner evolved. Initially, Efficiency Maine (housed within the Maine Public Utilities Commission) signed on as a supporter of the grant application. During 2010, the Efficiency Maine Trust was formed and split off from the PUC, taking the obligation to this grant with them. Over the course of 2010, it became apparent that renewable energy, while part of the Trust's statutory responsibility, was not in practice a priority; the Trust had no relevant expertise on staff. During Q1 of 2011, SEA attempted to rectify this situation by identifying an interested and capable individual at another Maine agency, the Office of Energy Independence and Security (OEIS), and negotiated the transfer of the support obligation from the Trust to OEIS. OEIS appointed Jennifer Puser to serve on the Steering Committee. OEIS's support,

\footnotetext{
${ }^{5}$ http://www.windpoweringamerica.gov/newengland/neweep/conference.asp.
} 
however, was tenuous. Newly elected Governor LePage established a different set of priorities, and amid exercising those priorities and addressing budget deficits, support for initiatives like this project were deemed no longer a priority. As a result, Ms. Puser moved on to another job, and the remaining staff were unable to secure a continuing role. Our efforts to maintain a Maine government entity on the Steering Committee hit a dead end. SEA did not have a Maine government entity participating on the Steering Committee after this departmental change, although other non-governmental entities in Maine were engaged through other means.

\section{Shift in Approach}

Additionally, with DOE Field Project Office's assent, NEWEEP changed the initial proposed approach to the structure of the 2011 Conference. ${ }^{6}$ Originally, NEWEEP had proposed a two-day conference co-hosted with the Utility Wind Integration Group (UWIG). NEWEEP had planned for UWIG to organize a wind integration workshop on Day 1, and planned for a NEWEEP conference on Day 2. The event was consolidated into a one-day conference. The proposed change in approach was based on the fact that UWIG's typical professional audience (day 1) was quite familiar with the Northeast wind-integration information, which lessened the need to dedicate a full day to this topic. Instead, UWIG included a session on integration in the NEWEEP agenda and was able to reach a broader audience than it would have with the original concept. The economies realized by compressing the meeting from two days to one day likely increased participation of the event. UWIG also committed to sponsoring the NEWEEP conference/workshop.

\section{Unanticipated Project Expenses}

Due to a combination of factors NEWEEP's budget fell short of meeting the monetary needs to fulfill the envisioned deliverables. Therefore SEA sought supplement funding through (a) co-funding from other entities; and (b) seeking conference/workshop sponsorships. The following list details a few of the unanticipated expenses that NEWEEP incurred throughout the project:

1. Conference logistical planning and services - in the original project scope and budget, it was anticipated that NREL would handle all the logistics; NREL was unable to take on this role, so SEA assumed this role.

2. Annotated bibliographies - The need for collecting comprehensive research for each webinar topic became magnified as the project developed; this effort was deemed necessary to support the webinars but was not reflected in developing the initial budget.

3. Handling the webinar registration process and communications - fielding requests for information resulting from high visibility and successful project outreach; SEA handled this process in order to allow targeted follow-ups (reminders, feedback surveys, etc). NREL's technology - LiveMeeting - did not allow us the flexibility to modify the registration process as needed.

4. Steering Committee recruitment and encouraging participation - resulting from Steering Committee partner's funding loss, government reorganizations and lack of money at the state level for government functions.

5. Reporting Requirements - DOE's reporting requirements exceeded SEA's prior experience with Federal government reporting (under contracts to NREL) and exceeded the time budgeted.

\footnotetext{
${ }^{6}$ SEA confirmed with Dwight Bailey, DOE Field Project Officer, via a conference call on Monday, January 24, 2011 that the consolidation from two-days to one-day was acceptable and did not affect the expected deliverable or change the scope of the project in any way.
} 
Additionally, challenges to public acceptance of wind power throughout the region has mounted, and the Steering Committee and Conference Planning Committee committed to making the planned conference/workshop a larger and much more comprehensive effort than originally envisioned, addressing a wider range of issues, concerns and information (including misinformation) being brought forth throughout the region. Many aspects of the effort have led to greater-than anticipated expense. Examples include:

- The effort to identify and secure a larger and centrally-located conference facility;

- Time required to organize a more complex and comprehensive conference;

- Formulating, developing and organizing 4 workshops to be included as part of the conference;

- Developing pre-surveys intended to streamline the workshops;

- Development of ground rules for participants;

- Arranging to video record conference panel sessions to allow greater access to the proceedings;

- Exploration of developing a scholarship fund so that local government siting decision-makers (who often have no budget for such events) may be able to attend;

- Participation in additional meetings including a March, 2011 WPA meeting in Boston;

- Folding the UWIG integration workshop into this comprehensive conference;

- Development of sponsorship outreach materials and recruiting of sponsors. SEA contacted over 100 organizations to request conference and workshop sponsorship.

The objective was for the sum of conference revenue streams - from sponsorships, registrations and $\$ 10,000$ of grant funds initially designated for these purposes - to exceed conference expenses, creating supplemental funding to defray the greater costs associated with putting on the conference, offset the other increases identified above, and replenish the budget to allow subsequent webinars for the remainder of the grant term. SEA consulted with Dwight Bailey, DOE Field Project Officer, and confirmed that supplemental income from conference proceeds could be used to fund a portion of SEA's labor associated with these additional needs.

After grant funding was exhausted in Q2 2011, SEA continued to track labor incurred to execute the conference/workshop and the final webinar and included this labor total in the spending summary and cost share contributions report as in-kind contributions. Only SEA labor incurred after grant funds were exceeded were reported. SEA received written email authorization from Laura Merrick, DOE Contracting Officer, confirming the ability to apply SEA's uncompensated time towards the contractual shortfall in actual cost share attributable to other project participants. 


\section{Accomplishments}

Based on the registration numbers and participant's feedback, the webinar series was well-received and found to be useful and informative. Figure 4 demonstrates how participants rated their overall experience. It is evident from the overwhelming response and participation in the program that people within New England and all over the country are yearning for this type of objective and educational information.

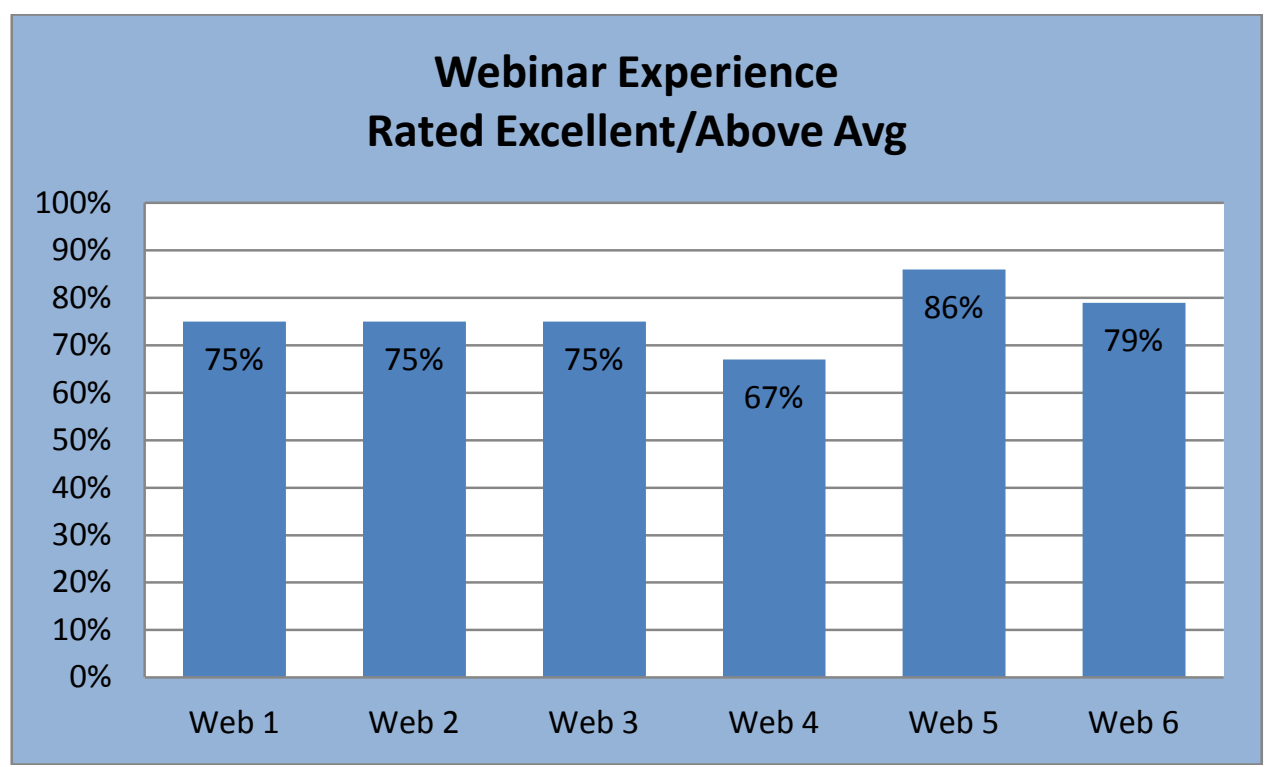

Figure 4 Overall Webinar Experience Rated Excellent/Above Avg

When participants were asked what NEWEEP could do to make their webinar experience better the following comments were collected:

- "I don't believe the experience could have been any better. It was well organized, the speakers were very informative, and the technical aspects i.e. slides, audio, etc. all worked well together."

- 'Please keep them going! I think they've been great, and of much help to broaden one's thinking and perspective."

- "Being able to download/print out the powerpoints in order to take notes on them would be helpful!"

- "Provide live video of the participants."

- "Try a more standard and easily accessible platform that does not require special software."

- 'Having 'lively' speakers is the key to keeping a webinar rolling - or any public info session for that matter. Not necessarily reading word for word on the page. It makes it more interesting and viewers are more apt to remember the key items when there is an enthusiastic person speaking. Not everyone has those skills. Myself included."

- "Limit the time to an hour at most. Preferably 30-45 minutes. Cut out some of the preamble to make room for the content, but 2 hours is far too long to stay engaged on a webcall."

- "Find a webinar service that will also interface with the Mac OS." 
The follow-up survey results from the webinar series provided NEWEEP with critical feedback that guided the development of future webinars and the conference/workshop. NEWEEP confirmed that the majority of those attending the webinars perceived the materials to be presented in a neutral/objective manner (See Figure 5 below). Nonetheless, those responding that did not rate the webinars as neutral and objective more often perceived a pro-wind than an anti-wind bias. Although NEWEEP made every effort to identify speakers that would present in a neutral/objective manner, the feedback indicated NEWEEP needed to review the presentation approach in an attempt to address the modestly biased pro-wind concern that seemed prevalent among the attendees. (On the other hand, it may be that many have decided on their positions and are not open-minded to factual data that contradicts their pre-held beliefs).

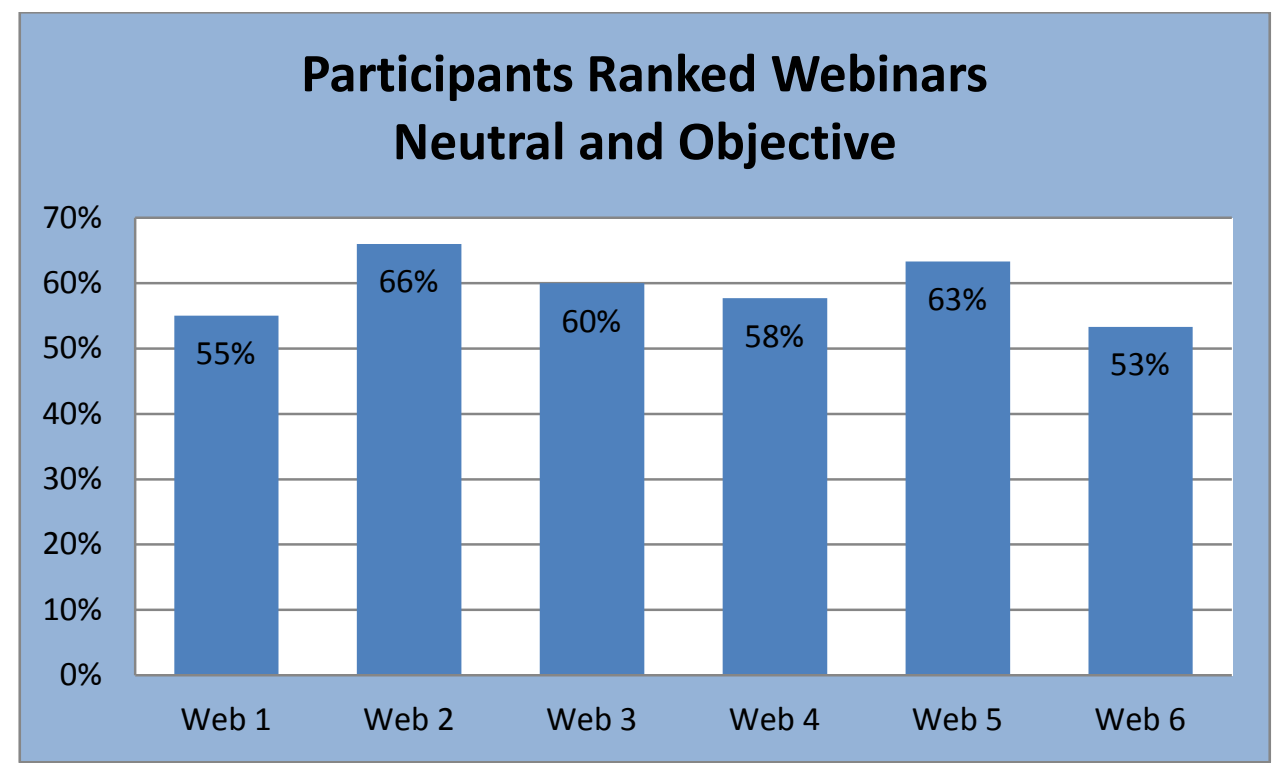

Figure 5: Webinar Presented in a Neutral/Objective Manner

When participants were asked what NEWEEP could do to present the topics in a more objective manner, the following comments were collected:

- "Objectivity is neutral; the webinar should bring out the real reasons why people are for or against. Myths or just feelings. Will not save our planet."

- "Each speaker should provide a bibliography of the sources he quotes."

- "Give a premise; give the research that supports the premise. Show what the opposition believes is not fact but unsubstantiated opinion."

- "Have a whole session on the problem of objectivity per se, with an analysis of certain studies on sensitive subjects."

- "Recruit speakers with either with opposing views or those who will present the negative side of the wind issue."

- "Don't use consultants that make their living off the subject matter. Academics, add in a permitting official from a town that's experienced with wind development."

- "I think you did a fine job of this, giving examples of real issues. It might have been good to invite a person who has seen their sleep disrupted, etc., to testify as part of this kind of a "wind as neighbor' focus."

- "Perhaps address some of the other fears that residents present ie, fire, blade drops, mammal and avian impacts, data that opponents present." 
- "We would have liked to hear more facts from people not involved in wind projects."

- "Identify problems encountered, and alternative development scenarios with reduced impacts."

- "Include panelists on both sound and vibration from areas or who have studied the issues in areas where turbines have been in use longer than in examples."

In addition to the materials developed, collected and distributed, NEWEEP also expanded on the already robust network of collaborators and outreach partners that were pivotal in the success of the project. From the evolving number of Steering Committee partners, the commitment from the conference/workshop planning committee members and with the growing number of outreach partners (over 35 organizations), NEWEEP accomplished its goal of disseminating accurate and objective information and effectively increasing awareness of the critical issues impacting siting of wind projects in New England. Figure 6 below summarizes participant's response when asked how useful it was to have the materials available for download following the webinars. NEWEEP's success was also reflected in the incredible response to our outreach efforts as seen in the number of registrations for the webinar series and the conference/workshop. Collectively, NEWEEP had over 2700 webinar and conference/workshop registrants consisting of the general public, siting decision makers, renewable energy business and associations and many others.

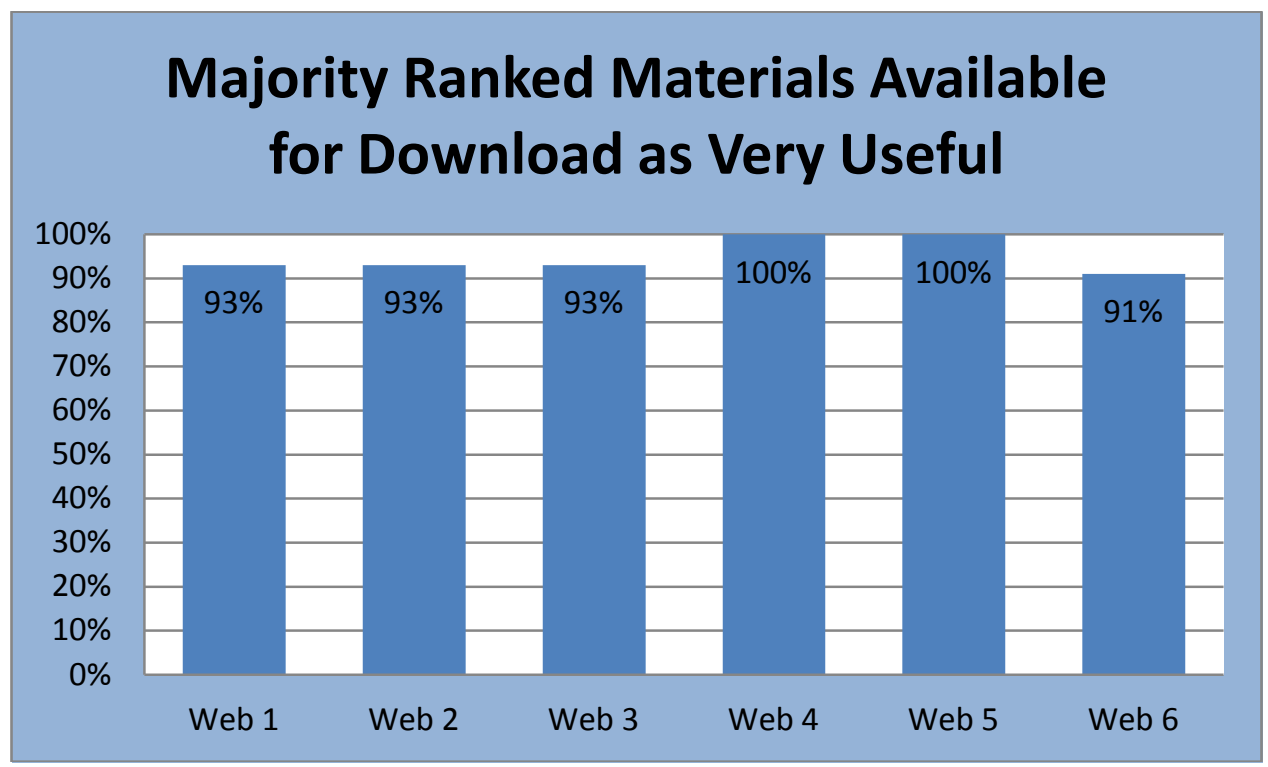

Figure 6: Usefulness of Materials Available for Download

The outreach materials developed for NEWEEP were designed to not only notify potential participants of future events but also to drive traffic to the NEWF/NEWEEP website and encourage signup to receive future webinar announcements and the NEWF newsletter to increase subscribership. When the project commenced in December 2009, this distribution list contained approximately 3,500 subscribers. As a result of the NEWEEP outreach efforts and other WPA outreach activities over the last two years, the distribution list now includes over 8,000 subscribers.

\section{SEA Receives Eastern Regional Wind Advocacy Award}

In May 2011 at the WPA All-States Summit, SEA received the Eastern Regional Wind Advocacy Award for its bold leadership and commitment in advancing wind energy in the East, relating to its execution of NEWEEP. The Summit attendees participated in an online survey to nominate individuals for various awards. NREL and DOE compiled and discussed the nominations and presented the awards at the Summit. This award is evidence of NEWEEP's efforts and impact on wind energy in the New England region. 


\section{Conclusions}

The public's need for reliable and objective information regarding wind energy siting in New England is palpable. Presently, wind generation under development in New England is handicapped by a dearth of information from all angles regarding the impacts of energy choices in general, and to wind energy in particular. Beyond the expected concerns expressed by abutters and those with potential views of proposed wind projects, well-organized campaigns opposing wind projects throughout the region have mounted, with local groups actively collaborating with each other and organizations interceding from beyond the location of proposed projects. The intent of NEWEEP was to spur discussion and progress on local wind siting issues by leveraging a collaborative effort of state, regional and federal resources to encourage the market's acceptance of appropriately-sited wind energy generation in New England.

From the perspective of the principal investigator on this grant, the following are some of the most important findings and lessons learned revealed through execution of the NEWEEP.

\section{Findings on Wind Public Acceptance Context and Landscape in New England}

\section{Process Trends: Projects and Communities}

- More than most places, New England is experiencing many points of friction around the siting and public acceptance of wind energy.

- The region has a generally environmentally-conscious populace, and many policies have been passed at the state level within the region to support renewable energy. Wind is by far the most available renewable energy resource to meet the demands created by these policies.

- Many communities and end-users desire their own wind turbine; several states have pressed forward with community-based wind power initiatives. The result has been an unusually high number and density of wind project proposal. Hundreds of proposed wind power installations are proposed ranging from single turbines to large wind farms. The New England Wind Forum tracks 270 projects operating or under development that have already been announced to the public, and there are numerous projects under consideration that will soon be added to that number.

- Yet New England's high population density and land use patterns bring these installations into increasing proximity to either abutters or locations that are highly valued for other purposes.

- The increasing size of commercial-scale wind turbines is increasing visual impacts and is often perceived to increase other impacts as well, often leading to calls for greater setbacks.

$\odot$ When wind energy installations are proposed:

- change is perceived as threatening

- public objectives can conflict

- Heated and emotional debates commonly result

- Siting decision-makers need:

- Accurate and objective understanding of the issues in order to make the best decisions

- Accepted and applicable standards, which are often absent

○ Siting decision-makers face:

- An environment rife with often conflicting information, competing claims, typically involving the blending of valid and baseless concerns expressed by both concerned stakeholders

- Insufficient independent, rigorous (scientific, peer-reviewed) data to address many of the claims and concerns brought up by concerned citizens and opponents

- A chaotic brew of fact, opinion, fear, hyperbole, disinformation; misinformation, or misunderstanding of complex systems. 
- Often presented with conflicting set of studies and 'facts,' which may have significantly differing degrees of academic rigor. In some instances, this difference may be representative of the strength of the evidence; in other instances, arguments and evidence presented may reflect either emerging information which has been less-rigorously studied but may be valid, or arguments that may never stand up to objective scrutiny. Local decision-makers are illequipped to tell the difference.

- A great deal of pressure.

- Increasingly, towns and municipalities are reacting with bylaws, ordinances, moratoriums.

- Often these are designed to provide time to make well-considered choices

- Just as often, these are being proposed as a means to preclude or delay projects

- Setback requirements contained in many of the proposed bylaws and ordinances are increasingly measured in miles, well beyond what past standards and what available data suggests is required to mitigate concerns other than visual impacts; likewise, sound thresholds in many of the proposed bylaws and ordinances are well below past standards and what available science and evidence would dictate.

- Decision-makers in these communities may believe they are passing reasonable criteria for well-sited wind, often not understanding their choices may be 'prohibitive' in nature.

- On the other hand, such bylaws and ordinances may be understood as a decision that 'wind is not appropriate here'. If well-reasoned and fact-based, such choices should be accepted.

\section{The Players}

- Participants in siting decision-making and impacting what constitutes public acceptance include:

- Project proponents. Information on impacts presented by proponents may or may not be accurate and factual, but this information will not be perceived as without commercial interest.

- Open-minded abutters, community, citizens groups with valid concerns, looking for information and answers to determine whether they will find wind to be a good neighbor, and whether actual impacts will align with projected impacts.

- Opponents, often falling into several subcategories:

- 'Skeptics', who may be disinclined towards wind, and will require a high burden of proof to be convinced otherwise.

- 'Character of Place' groups... "In favor of wind, but not here." While these opponents are often labeled as NIMBY, use of such a label appears to be disrespectful, counterproductive, and ultimately oversimplifies motives.

- The 'Ideologically-Opposed'. These either include, or are influenced by, a series of increasingly sophisticated and networked groups, often from outside of the community and sometimes from outside the region. These entities will frequently disseminate packaged information ranging (in our opinions) from raising legitimate questions to rhetorically brilliant disinformation designed to paint wind in the worst possible light.

- Community-based abutters, who perceive (and will receive) minimal if any upside from the wind energy installation and therefore are resistant to bearing impacts.

- All of these 'opponent' groups are observed to be frequently sharing and exchanging information, arguments, and game plans that have been successful in derailing proposed wind projects elsewhere, often provided by the ideologically-opposed.

\section{Trends}

(-) The level of emotion and rhetoric is high, crowding out opportunity for decision-makers to consider facts.

- An increasing number of projects being turned down at the local level.

- When doubts are introduced, uncertainty favors the status quo (i.e. no project).

- Siting wind projects is getting harder, regardless of whether projects are well-sited or poorly- 
sited.

- Exhausting all appeals of wind project approvals is becoming the norm for opponents. Few projects have escaped the cost and delay of appeals. Very few appeals have succeeded.

\section{Public Acceptance Issues are Evolving.}

We have observed an evolution of public acceptance issues cited, concerns raised and arguments leveled in response to wind projects throughout the region.

- Wind's early growth phase. During this phase, prior to the commencement of NEWEEP, the primary issues impacting public acceptance were aesthetics, as well as impacts on birds, bats and wildlife. Sound was typically a lesser issue, in part due to smaller turbine sizes, although instances of installations with sound complaints began to emerge as well.

- Rapid Growth in installations. As actual installations in the region started to multiply, and experiences elsewhere (and opponent arguments honed in the context of those experiences) became readily shared via the internet, the focus on impacts on abutters and those with views of projects became more prevalent. These issues included the impact of sound, shadow flicker and more broadly, health impacts, on abutters; safety from blade throws or ice throws; impacts on property values of abutters' homes. As many projects were proposed for scenic or recreational areas, concerns over negative impacts on tourism or recreational values joined the aesthetic concerns. And habitat fragmentation from clearings and roads was added to the list of wildlife concerns. Most recently, some groups have focused on the issues of water pollution resulting from increased runoff or explosives residue during the construction phase of mountaintop projects where bedrock blasting is often required.

- Offshore. With the advent of offshore wind development, public acceptance issues relating to the aquatic environment, fishing, shipping, water recreation and tourism impacts have been added to the dialog. The scope of visual impacts expanded, spanning many miles from beachfronts with particularly high property values, where those potentially impacted often argued that existing studies of wind power's impacts on property values didn't apply.

- Categorical arguments against wind. During the course of NEWEEP, a new set of public acceptance issues and arguments came to the forefront: categorical opposition to wind power in general, regardless of whether it was well-sited. Several shifts in the landscape have set the stage for these arguments.

- Shifting economics. The impact of sharply falling natural gas and electricity prices driven by the advent of shale gas and the recession have increased the relative cost of wind power compared to non-renewable sources, making it harder to justify the investment in wind power.

- Shifting public priorities. The recession, as well as a shift in general political rhetoric, has stimulated a shifting of priorities among much of the public, with long-term environmental sustainability often seen as a less pressing concern relative to short-term immediate economics. With housing prices down and high unemployment, there is economy-wide pressure to reduce direct expenditures, often at the expense of ignoring indirect, external or deferred cost impacts.

- Capacity Surplus. The recession has also exacerbated an electricity supply glut in New England. When wind power is helping to meet growing demand, the electric market is welcoming of additional supply of all stripes. With a surplus and reduced demand due to the recession, successful wind siting will spell deteriorating economics for electricity generation incumbents. Owners of incumbent generators have started to resist the expansion of wind, not only fighting against any wholesale electric market rules perceived to give wind power an advantage and looking to undermine policies supportive of wind power, but also providing fodder for the public acceptance arena by raising the question of whether wind is needed when there is surplus supply. 
- Transmission Expansion Costs. As wind power penetration has increased in the region, it has become apparent that costly additional transmission facilities may be required to tap more of the substantial wind resources in Northern New England. Debates continue over who might build such transmission, what it would cost, how it would be paid for, and who would pay for it.

These shifting conditions have provided the foundation for a new series of arguments entering the public acceptance dialog. This categorical opposition to wind, regardless of whether it is well-sited to minimize actual impacts on host communities, abutters or wildlife, has grown to arguments including:

- Cost and Subsidies. Even when a wind project is economically viable for those involved, opponents are increasingly decrying the public cost of subsidy and the direct cost of wind power relative to spot electricity prices.

- Integration Costs. Arguments have been put forward that wind power's variability is a critical shortcoming, degrading reliability, and increasing the need for 'backup supply' (what the industry refers to as capacity and operating reserves). If fossil-fueled power plants must keep running, questions are raised, and assertions put forward, about whether the promised reduction in fossil fuel use and emissions materialize.

- Reframing. The general argument framework for categorical opposition to, or question of, wind has emerged: 'wind doesn't deliver benefits'... so no impacts, and no mitigation, is worth it.

\section{Reframing Wind Public Acceptance: Undermining Wind's Legitimacy.}

Increasingly, well-organized and networked organizations falling largely into the ideologicallyopposed and character-of-place categories have spread a series of arguments, now commonly adopted by local citizens groups including community-based abutters and skeptics, raise questions or make assertions that attempt to undermine wind power's legitimacy. The argument generally consists of the argument ${ }^{7}$ that we "...support sound scientific solutions - and wind power is not acceptable as it fails to deliver...', because:

- It is not a technically legitimate solution for our grid;

- It doesn't meaningfully reduce $\mathrm{CO}_{2}$;

- In is not a commercially viable source of energy on its own;

○ It is not environmentally responsible.

These assertions have been supported by an increasingly sophisticated blending of elements of data and facts accurately presented, issues where wind advocates have overstated the case, truthiness, ${ }^{8}$ false straw men, oversimplification of complex systems and science, brilliant rhetoric, and mockery. The mix can be pretty compelling to a lay audience, or in the least, can often successfully sow the seeds of doubt that favor the status quo (i.e. no wind power).

"Once you fully absorb the understanding that wind power does not work, then you can see the foolishness of saying that it is OK if it is "sited properly." \{Exactly what is proper siting for something that does not work? ?"?

\footnotetext{
${ }^{7}$ Paraphrased from Droz, John, An Analysis of Anti-Wind Strategies, May 16, 2009, last accessed April 11, 2012 at http://www.northnet.org/brvmug/WindPower/AntiWindStrategy.pdf.

${ }^{8}$ Truthiness, as coined by comedian Stephen Colbert, is defined as a "truth" that a person claims to know intuitively "from the gut" without regard to evidence, logic, intellectual examination, or facts. (Wikipedia)

${ }^{9}$ Droz (2009)
} 
It is into this context that NEWEEP offered a source of information from neither project proponents nor abutters, in an effort to present whatever well-grounded factual information was available to educate citizens and siting decision-makers.

\section{Findings on Webinars and Conference/Workshop}

Our objective with NEWEEP was to present the best data we could find and leave the interpretation up to the audience, members of which may reach different conclusions based on the information presented as well as the Q\&A and discussion in each session. Therefore, in the spirit of the NEWEEP endeavor, specific findings relating to the topics examined in the webinars and conference/workshop are to be culled from the web-based NEWEEP materials. We feel it is best to let the proceedings speak for themselves without interpretation

\section{State of the Art of Knowledge on Issues Impacting Public Acceptance of Wind Power}

- On some topics - such as shadow flicker - there is a lot of fairly definitive information available. On other topics - such as sound - there are identified data gaps, and needs for additional research.

- There is a lot of myth and inaccurate info and assertions impacting the public dialog.

- There are certain issues which appear to have little or no factual basis to be cause for concern when it comes to public acceptance. Examples include worries that wind power can induce epileptic seizures, or that wind power production in New England will not reduce fossil fuel use and emissions. Such topics appear to be largely kept in play due to the innuendo propagated intentionally or echoed by those who have not been able to, or taken the time to, filter credible from non-credible assertions.

- For other issues, the impacts merit further discussion. Many issues are site-specific, terrain- or distance-specific; others are a matter of degree, interpretation, receptor sensitivity or expectation.

- Finally, there are numerous topics ripe for further research which could advance the public acceptance/siting dialog. Where material uncertainty remains, or the available research is not directly applicable, definitive, corresponding to locations viewed by stakeholders as comparable to a specific location where a wind project is being proposed, the uncertainty will increasingly stimulate cautious reaction on the part of decision-makers favoring the status quo (no wind power project).

\section{The NEWEEP Sessions and Perspective are Valuable Even if Imperfect}

○ As noted earlier, the sessions were quite well-attended. There is a lot of interest in what NEWEEP offered, which was clearly meeting a need for an independent place to go for credible, objective information.

- The products of the effort - the materials posted on the New England Wind Forum web site are useful and being used.

- There is a hunger for more information. Many questions were raised that the funded scope of NEWEEP were unable to answer. NEWEEP's approach seems to be productive for participants. It is important to note that no matter how good a job one does in executing a NEWEEP-like approach, you can't (and won't) please everyone. No matter how objective the presentation and speakers, objectivity is a worthy goal, and an objective worth striving for. In executing NEWEEP, we feel that we were close to achieving a realistic goal, with feedback on whether the webinars/discussion were framed in an objective/balanced manner rating roughly 
3.5 on a scale from 5 (pro-wind bias) to 3 (neutral/objective) to 1(anti-wind bias). Participants ranked their overall webinar experience as roughly 4 on a scale from 1(poor) to 5 (excellent).

\section{Accessibility is important}

O It is hard for many in the target audience to travel far to attend an in-person event, and in particular, members of the general public and local siting decision-makers are hard-pressed to fund travel costs and event fees out of their own pockets (or, since they are not usually full-time energy processionals, to take off a day of work in order to engage).

- It is critical to make available participation available at low cost (preferably no cost).

○ For this reason, the webinar format appears to be a very effective vehicle for educational efforts on wind public acceptance.

- It is also very difficult to select a time for a conference or webinar during which many on the target audience do not have other commitments. For this reason, having an on-line location to post presentations, audio recordings, bibliographies, and Q\&A transcripts helps facilitate the materials reaching a much broader audience and leverages the reuse of the materials.

- We envisioned the press as a target audience. No press attended the conference. It may not be realistic to expect press to attend events for which they must pay a registration fee.

\section{Lessons Learned for Future Efforts to Support Public Acceptance}

- Perception is Reality. Those looking to advance a fact-based dialog on wind power siting must be aware of and address the information as perceived. This observation has several implications:

- Education efforts need to address the conceptions and misconceptions that exist, as influenced by the factors addressed above.

- Issues for which there is little evidence of concern may still require an educational effort.

- Information is filtered by many stakeholder based on where it comes from. Information may be accepted or dismissed by stakeholders based on who puts it forth, who has a commercial interest in it, or who pays for it.

- The media needs education. They are prone to hyperbole and focusing on dissent and complaints, and can sometimes badly distort the prevalence of issues, impacts or concerns. As a result, the media can sometimes magnify or inflame fear of impacts. On the other hand, the media does provide a valuable avenue for information dissemination.

- The experience with wind power siting and public acceptance has many elements in common with the siting of other infrastructure. And like other large infrastructure projects, change is threatening, and history has shown that unanimous support for such projects is highly unlikely. You can't make everyone happy. Change is threatening.

- Small minorities (in many cases) have undesirable impacts thrust upon them, often without receiving any project benefits.

- It is in the interest of wind power developers and those who support wind to avoid surprises (unanticipated impacts) and manage expectations. If supportive abutters (pre-project) become opponents (post-operation), subsequent approvals become harder for everyone else.

- Wind turbine sound presents unique challenges, for a number of reasons. Audibility is not the same as, and does not equate to, annoyance. Sensitivity can vary by a number of factors, including attitude (predisposition to wind power, whether wind can be seen, whether an abutter benefits financially), 'place identity', and individual sound sensitivity. These differences promote discord. Furthermore, most research focused on sound amplitude rather than modulation, leaving gaps in understanding impacts. 
- 'Objective' is in the eye of the beholder.

- A significant challenge is presented in generating and presenting independent, credible, peerreviewed, objective data on wind power impacts:

- Independent and government funding sources are scarce.

- If industry is the only source of available funds to pay for research and educational efforts, how can such efforts at research or NEWEEP-like outreach be funded without 'tainting' the results by virtue of the funding source?

- Caution to wind industry and proponents: Arguments for further study of health impacts might be a delay tactic or red herring, even if research can definitively conclude that exposure to wind power does not cause a unique disease, ${ }^{10}$ wind proponents being dismissive of health impacts on people that are stressed and losing sleep is not constructive, and may backfire.

- For the range of public acceptance issues potentially impacting abutters and neighbors of wind power projects, important questions to be able to understand and answer include:

- Are undesirable impacts happening?

- If so, in what numbers? At what distances? Under what circumstances?

- What percentage of the populace (abutters, and beyond) is potentially impacted? How often are they impacted? (a few hours/yr, or constant?)

- What degree of impact is acceptable, for society? (see opponent's reframing arguments, above).

- What mitigation is appropriate for those impacted?

- Are predictive tools working, or are people being impacted to a greater degree than projected?

O This is critical, so that the numbers impacted (frequency and magnitude) fall within what has been deemed acceptable.

- In conducting future NEWEEP-like efforts, the constitution of a steering committee to oversee the effort is important for supporting the perception of the information provided:

- Research institutions are desirable partners both for their independence and the leverage they can bring to efforts by virtue of their expertise and resources.

- The Independent System Operator is a very constructive party to engage. They are by definition technology-neutral, and are therefore the most reliable and credible authority on actual system impacts.

- Representatives of state administrative agencies are an excellent resource, and in our experience, are genuinely and generally supportive of a search for objective information rather than attempting to support wind power projects that are not well-sited. They tend to share a generally understanding that problem projects - those that reach commercial operation and have impacts in excess of what the neighbors and community expected undermine the prospects for well-sited future projects. It is important to understand however, that when they work for administrations that have been supportive of wind power policies, they can be perceived by some of those opponents whose minds are already made up as pushing a pro-wind agenda. Therefore, their involvement is not by itself sufficient.

- In designing and executing NEWEEP, we felt it important to have the voice of

\footnotetext{
${ }^{10}$ For example, a recent Massachusetts Department of Environmental Protection/Department of Public Health study concluded "that there is no evidence for a set of health effects...that could be characterized as "Wind Turbine Syndrome." See: Massachusetts Department of Environmental Protection and Massachusetts Department of Public Health, Wind Turbine Health Impact Study: Report of Independent Expert Panel, January 2012. Accessed at http://www.mass.gov/dep/energy/wind/turbine impact study.pdf.
} 
environmental advocates (non-governmental entities with renewable energy expertise) and wind industry, to help identify and prioritize the priority public acceptance issues. NEWEEP accomplished this through involvement on the Steering Committee of one entity, Renewable Energy New England, representing industry and environmental organizations. Involvement of any industry representation, no matter how trivial, may be cited by wind opponents as evidence of bias, unless countered by direct involvement in a comparable role. More generally, some participants in NEWEEP events suggested greater involvement of citizens groups and skeptics in the events themselves. ${ }^{11}$

O It is important to the credibility of such outreach and education efforts as NEWEEP to incorporate the perspectives of skeptics. During the course of this effort, NEWEEP committee members reached out to several potential speakers and participants, engaged in dialog with several, and reviewed materials developed by a variety of opponent groups.

O Ideally, NEWEEP could have done better in incorporating the perspectives of skeptics more directly. However, our experience suggested that it is difficult (but not impossible) to find parties in the 'skeptic' camp that are willing to engage constructively. The more rejectionist 'character of place' and 'ideologically-opposed' groups are easier to identify. However, individuals in those camps may be reticent to participate in a process whose objective includes facilitating the siting of well-sited projects, even if it also espouses to avoid construction of poorly-sited projects, as doing so might validate any material fraction of wind projects as well-sited. Despite the difficulties, engaging opponents appears important to a credible process.

- Many wind siting-related events during the past few years have turned heated and acrimonious. NEWEEP sought to facilitate a constructive dialog focused on the facts and avoiding acrimony to the extent possible. In webinars and conferences, it is critically important to welcome challenging questions of the speakers, and to not filter the question and answers. The Q\&A was often the most interesting and illuminating part of the events. It is equally important to minimize grandstanding, audience members hogging the microphones for extended speeches, and inflammatory and disrespectful language. NEWEEP addressed this balancing act in the webinars by having the moderator read submitted questions in the order posed without censorship (although occasionally with slight 'editing' to clarify or keep the language civil). In the conference, a set of ground rules was presented for review and acknowledgement at registration and throughout the conference, and a mixture of written questions and questions posed at microphones was used. In general, we feel this approach worked very well in striking the desired balance, although we acknowledge that some audience members at the conference felt frustrated that they would not have the opportunity to speak directly.

- The press needs to be engaged, as too often it is not a productive contributor to the dialog.

\section{Realistic Objectives}

It is unrealistic to expect any education and outreach effort like NEWEEP to convince everybody to accept and be compelled by the findings, even when driven by credible, objective evidence and rigorous, peer-reviewed research. In the current context and landscape, described above, the prevalence of conflicting information, misinformation, and contention is increasingly resulting in extended wind power siting battles and an increasing frequency of siting denials, appeals, restrictive

\footnotetext{
${ }^{11}$ There was a concerted effort to engage these perspectives in the conference/workshop, with mixed success.
} 
ordinances, bylaws and moratoria. Fear, hyperbole, and invective aimed at siting decision-makers is drowning out objective data, resulting in a polarized dialog often characterized by indecision and defensive rulings. These results are occurring in broad brush-strokes, painting appropriately-sited and inappropriately-sited projects alike. In this context, we believe that a reasonable objective for a NEWEEP-like effort is to stem the conversion of undecided or skeptical people into closed-minded opponents, while building the willingness of generally open-minded people to actively support appropriately-sited wind based on reasoned data and rational deliberation.

\section{Recommendations}

\section{Continuing NEWEEP}

Our experience with NEWEEP, and the feedback received on these efforts, suggests that the approach used works well, and should be continued in some manner, with elements of the NEWEEP approach but evolving to utilize the lessons learned. The scope of NEWEEP - education and outreach on targeted issue - is part of a broader set of parallel needs which includes filling research gaps and perhaps developing standards. We feel a combination of webinars and in-person events can help create a community pulling in a constructive direction.

The feedback received supports a continuation of the NEWEEP effort, and therefore we recommend DOE consider a mechanism for continued funding support, perhaps in a matching-funds manner to stimulate co-funding. Since DOE funds for continuation are not currently available, we intend to investigate alternative funding models to perpetuate some ongoing effort, perhaps in concert with other regional stakeholders.

Future funding presents both a challenge and, as noted above, a dilemma. Funding from non-industry sources - state governments, non-profits, and foundations - is particularly scarce in the current recession. Those that may benefit most from investing in such efforts - the wind industry - would undermine the perceived credibility if they were to fund the effort, even if exercising no operational control over the effort. Participant fees must be kept low(or zero) to make the effort accessible to its target audience. Modest co-funding from sponsors helped fund the NEWEEP conference/workshop, and may provide a model to help such an effort move forward. However, at this juncture, if such support appears necessary but insufficient in likely magnitude to support an effort of even a fraction of NEWEEP's past scope. An expression of DOE's continued interest and, at a minimum, ongoing support in providing, maintaining and updating an on-line repository for NEWEEP materials would increase the odds of advancing the effort.

\section{Improving on NEWEEP}

If NEWEEP were to be continued, we would recommend making modest changes to the approach and its execution:

- Expanding the 'NEWEEP Network' beyond the steering committee level to create ways in which other stakeholders can participate in the project.

- Involving skeptics to a greater degree.

- Developing guidance to developers on how to do things right, including outlining what decision-makers should expect of developers.

- Posting webinar materials sooner after events (there was a 2+ week lag after webinars, longer for the conference).

- Making webinar PowerPoints available to the webinar audience prior to the webinar

- Continuously augment the topical bibliographies. 